\title{
Artículo Especial
}

\section{Responsabilidad profesional médica: Diagnóstico y perspectivas}

\author{
Carlos Pizarro $\mathbf{W}^{1}$.
}

\section{Perspectives in medical liability}

The progressive increase of medical negligence law suits requires an updated analysis of the current situation of medical liability in Chile. The application of a new criminal procedure will avoid criminal prosecution of doctors, transfering to the civil courts the pecuniary sanctions for malpractice. Medical negligence and damage inflicted by doctors that require compensation are explained. The most likely evolution of medical liability is proposed, through an increase in civil liability insurances and the necessary standardization of rules applicable to profesional liability (Rev Méd Chile 2008; 136: 539-43).

(Key w ords: Criminal law; Malpractice; Medical liability)

${ }^{1}$ Doctor en Derecho, Facultad de Derecho de la Universidad Diego Portales. Santiago, Chile.

$\mathrm{L}$

a responsabilidad en el ámbito del ejercicio de la medicina ha adquirido en nuestro país una relevancia insospechada hasta hace un par de décadas atrás. Actualmente, las demandas por mal praxis o resultados adversos contra los médicos y establecimientos hospitalarios, públicos o privados, se han acrecentado significativamente. Según estadísticas del Servicio Médico Legal para el año 2003, se ingresaron 508 casos de responsabilidad profesional médica ${ }^{1}$

Los médicos pueden quedar sujetos a distintos tipos de responsabilidad, cada una de las cuales tiene un régimen legal específico. En primer lugar, la responsabilidad penal por "negligencia culpable" prevista en el artículo 491 del Código Penal. En segundo orden, la responsabilidad civil, ya sea de manera concurrente o autónoma al ilícito penal. A través de aquella, la víctima busca una reparación

Correspondencia a: Dr. Carlos Pizarro W. República 105, Santiago. Teléfono: (56-2) 6762640. Fax: (56-2) 6762641. E mail: carlos.pizarro@udp.cl pecuniaria al daño ocasionado. En tercer lugar, cuando la negligencia médica acaece en un hospital público, corresponderá aplicar la responsabilidad administrativa del respectivo Servicio de Salud. Esta responsabilidad, según dispone el artículo 38 de la citada Ley, se basa en la "falta de servicio", expresión que ha sido entendida como una responsabilidad objetiva, pero que en otros casos se ha conceptualizado como subjetiva. En realidad, el problema es más semántico que real, pues en los casos en que se ha entendido como objetiva, es fácil advertir la existencia de una negligencia ${ }^{2}$.

La responsabilidad penal. La responsabilidad penal busca sancionar con una pena privativa de libertad al médico que se ha apartado de su lex artis en la ejecución del acto médico. Sin embargo, es inusual que un médico sea privado de libertad por una sentencia condenatoria. En el peor de los casos han accedido a una forma alternativa del cumplimiento de la pena o beneficios carcelarios, pues suelen beneficiarse de atenuantes como la irreprochable conducta anterior.

Con la entrada en vigencia del nuevo proceso penal, la persecución penal de los médicos por 
actos negligentes debiera ir en franca retirada. Antes de la vigencia de esta reforma, era usual que los abogados buscaran "criminalizar" los actos de los médicos para exigir la indemnización civil en el mismo proceso penal. Sin embargo, el nuevo Código Procesal Penal restringe en forma significativa la posibilidad de intentar la acción civil en el proceso penal. Por consiguiente, es posible vaticinar que los problemas de responsabilidad médica serán conocidos por los jueces civiles más que por los jueces penales. Esta política criminal es muy acertada, atendido que no es eficiente la persecución criminal de las actividades profesionales al generar un aumento de los costos de la atención sanitaria ${ }^{3}$.

Responsabilidad civil. Al igual que en la mayoría de los derechos extranjeros, la evolución de la responsabilidad médica está marcada por la búsqueda de una indemnización en dinero. Aunque parezca curioso, para determinar las reglas aplicables a los médicos, es necesario distinguir si el acto médico fue ejecutado en un hospital público o en el marco de la profesión liberal. Tratándose de un hospital público existirá responsabilidad si puede calificarse la actuación como "falta de servicio". La Ley № 19.966 de 2004, conocida como "Ley del Auge", consagra reglas particulares para las negligencias médicas acaecidas en hospitales públicos. Aquí el paciente adquiere la categoría de usuario de un servicio público. No existe una relación contractual entre el paciente y el médico tratante, que a su turno, es un funcionario público. Por el contrario, en el ámbito privado, la relación entre el paciente y el médico y, asimismo, aquella entre el paciente y la clínica o establecimiento privado de salud, constituye un vínculo contractual de derecho privado.

Este doble tratamiento de la responsabilidad médica no se justifica. El derecho debería responder con las mismas reglas, ya sea que el acto médico tenga lugar en un hospital público o privado. No existen razones válidas para justificar este tratamiento desigual. Además, se crea una incertidumbre innecesaria para los destinatarios de las normas, afectando la seguridad jurídica.

Responsabilidad contractual y extracontractual. Todavía para que el asunto sea aún más complejo, existen reglas distintas según exista un contrato entre el paciente y el médico o no se haya trabado una relación contractual precedente. En el primer caso, se trata de la responsabilidad contractual y en el segundo de aquella extracontractual. También se rigen por reglas distintas. No es lo mismo causar un daño a un paciente con quien se ha celebrado un contrato -el cual puede ser de palabra o por escrito- que la situación en que el médico, por ejemplo, atiende de urgencia al paciente y no hay acuerdo contractual. Este doble tratamiento también resulta criticable. Nada justifica la existencia de reglas distintas para la indemnización de los perjuicios ocasionados según exista o no contrato entre el paciente y el médico. Por lo mismo se propone unificar las normas aplicables a la responsabilidad médica, sin importar si la negligencia tuvo lugar en un hospital o en una clínica, ni tampoco si existió o no contrato. Un sistema uniforme permitirá a los destinatarios de las normas conocer los riesgos que enfrentan en el evento de un resultado adverso.

La culpa y el error médico. Un médico debe responder cuando su conducta se califica de culpable. La culpa constituye un elemento esencial para que un médico quede obligado a indemnizar al paciente. Por eso es usual señalar que los médicos tienen "obligaciones de medios" y no de "resultados", ya que comprometen hacer todo lo posible por lograr una curación, pero no aseguran un resultado específico.

El médico puede ser culpable, de una parte, por incumplimiento de la obligación de informar, lo que implica la realización de un acto médico sin un consentimiento informado del paciente y, por otra, puede ocurrir que el acto terapéutico no sea realizado de una manera correcta ${ }^{4}$.

La obligación de información. La obligación de información del médico puede ser más o menos intensa dependiendo de la prestación involucrada. Así, suele indicarse que tratándose de una cirugía estética existe un deber mayor de información al paciente. Al no concurrir una finalidad terapéutica, el médico debiera informar no sólo los riesgos normales, sino también aquellos excepcionales. Lo usual será que exista un contrato entre el médico y el paciente, estando a cargo del primero acreditar que cumplió con la obligación de información. Se trata de una regla específica para la 
responsabilidad contractual -artículo 1.547 inciso 3o del Código Civil-, según la cual el deudor de la obligación debe probar su ejecución.

Sin embargo, en Chile, la obligación de información ha tenido un escaso desarrollo. No se conocen sentencias condenatorias por infringir el deber de información. La razón puede estar en que la infracción al deber de informar se traduce sólo en la pérdida de una posibilidad. Es decir, el paciente queda privado de la opción entre someterse o no al tratamiento. Se trata de un problema de causalidad. Al no informarse de un riesgo y habiéndose verificado, no procede indemnizar el daño constitutivo del riesgo acaecido, el cual está dentro de las posibilidades, sino que sólo correspondería indemnizar el daño de la pérdida de opción, cuya cuantía es difícil de determinar. Este rubro de daños "la pérdida de una posibilidad" no ha tenido recepción en los tribunales nacionales ${ }^{5}$.

La culpa en el acto médico. Una cuestión diversa ocurre con la culpa en el acto médico. El médico se encuentra obligado a entregar al paciente o enfermo, una prestación concienzuda, atenta y conforme a los conocimientos de la ciencia. Se le exige un comportamiento acorde a los conocimientos actuales de la ciencia.

En Chile, según ya hemos señalado, la prueba de la diligencia corresponde al deudor. Es responsabilidad del médico probar que actuó con la diligencia debida. La pregunta que surge en el derecho es cómo se determina la diligencia exigida al médico. O, en sentido inverso, cómo se construye la noción de culpa médica.

Para encontrar una respuesta, debe diferenciarse entre el error médico y la culpa médica. Mientras la culpa es el hecho de no comportarse como lo habría hecho un médico informado y competente en las mismas circunstancias; el error, en cambio, no genera responsabilidad, pues cualquier médico bajo esas circunstancias también se habría equivocado. No puede condenarse un médico que comete simplemente un error. Pero sí procede sancionar a un médico que no se comporta como debía comportarse.

Para fijar el modelo de conducta apropiada para cada situación específica, los jueces y los abogados recurren a los peritajes a fin de determinar la denominada lex artis, por la cual se rigen los profesionales. Debe configurarse una culpa técnica; es decir, a través de una comparación entre lo que se debería haber hecho y aquello que se hizo existe una discordancia. El médico no actuó como debió hacerlo. Si el médico se comporta en conformidad al estándar de conducta que se le exige no habrá culpa. Para identificar la culpa debe analizarse la conducta del médico en el diagnóstico, el tratamiento, la aplicación del tratamiento y la vigilancia del paciente. La culpa en el diagnóstico es una situación de excepción, siendo sólo posible cuando se trata de un diagnóstico usual, cuya equivocación revela una negligencia severa. El tratamiento y su aplicación pueden dar lugar a una culpa médica cuando existe un defecto técnico en su ejecución conforme a un estándar de un médico normal y medio. Aquí la culpa asume distintas manifestaciones. Puede concurrir la culpa por ignorancia. El médico no conoce la técnica apropiada. Puede verificarse la culpa por negligencia u omisión, es decir el médico no actúa en la forma que debió actuar. También hay culpa cuando el médico actúa de manera imprudente. Esta forma de culpa consiste en un actuar apartado del estándar exigible o, una culpa por acción. Aquí existe un exceso en el actuar que resulta reprochable. Por último, la culpa puede ser infraccional cuando el médico incumple un deber previsto en la ley. Por ejemplo por infracción al reglamento de hospitales y clínicas privadas.

En cuanto al deber de vigilancia, el médico debe cuidar al paciente, ya sea de manera personal o a través de un subalterno.

Ahora, no debe olvidarse que la medicina implica riesgos, a los cuales, por regla general se somete de manera voluntaria la víctima. En efecto, el paciente se somete en forma voluntaria al tratamiento para lograr un fin terapéutico. Esto no contradice que el paciente se encuentra en la necesidad de recurrir al médico, pero tampoco descarta la existencia de una voluntad para asumir el tratamiento y sus riesgos. Por lo mismo, el que se verifique un riesgo previsto no implica de manera necesaria culpa médica. Eso sí, el médico debe informar dichos riesgos, para que el paciente pueda escoger entre someterse al tratamiento o descartarlo.

Es usual que se señale que los peritajes no son siempre un medio idóneo atendida la solidaridad entre los médicos. Sin embargo, esa intuición 
contrasta con el trabajo efectuado por el departamento de negligencias médicas del Servicio Médico Legal, cuyos informes en no pocos casos resulta desfavorable para el profesional.

En definitiva, la culpa médica consiste en un comportamiento que se aparta de los usos normales de la medicina, ya sea por ignorancia de la técnica apropiada o por una actitud temeraria en el acto médico.

Atendido que la medicina contiene un componente aleatorio en cuanto a sus resultados se justifica que sea la culpa el fundamento para hacer responsable al médico. La culpa debe continuar siendo el fundamento de la responsabilidad médica.

Qué daños se indemnizan. El daño es un elemento esencial de la responsabilidad civil en general. Sin daño no hay nada que indemnizar. Los daños por negligencias médicas no se diferencian de hipótesis generales de responsabilidad civil. Debe distinguirse entre daños materiales y morales. En los primeros se distingue el daño emergente representativo de los gastos en que haya incurrido la víctima: costo de la intervención, traslados, insumos, etc. Y, además, el médico puede quedar expuesto a indemnizar el lucro cesante que corresponde a los ingresos no percibidos por la víctima en razón de la negligencia. Así, por ejemplo, remuneraciones o parte de éstas al no haber trabajado la víctima por un período de tiempo. En cuanto al daño moral, sin duda este rubro de indemnización ha adquirido una presencia exorbitante en los tribunales de justicia. El daño moral consiste en el dolor, pesar o angustia de la víctima. Pero no se agota en esta manifestación, sino que comprende también el daño estético, la pérdida de actividades recreativas o pérdida de capacidades fisiológicas. Ahora, el drama del daño moral es la forma de cuantificación. Los jueces han estimado que son libres para determinar de manera discrecional el monto de su indemnización. Éste es un concepto bastante confuso e imposible de cuantificar en forma objetiva. Los jueces a lo largo de Chile tienen formas de cuantificarlo sin criterios uniformes.

La responsabilidad del equipo médico. Cuando un médico realiza su trabajo con ayuda o asistencia de auxiliares que se encuentran bajo su subordinación o que son puestos a su disposición por el establecimiento de salud donde se desarrolla el acto médico, quien responde es el médico. Esta responsabilidad se denomina por el hecho ajeno. Su fundamento radica en que el médico tiene bajo su vigilancia y supervisión a los otros miembros del equipo. Sólo cabe considerar el médico, al menos desde el punto de vista de la responsabilidad civil.

Por el contrario, cuando varios médicos participan al mismo tiempo en una intervención médica, lo importante es averiguar si cada uno de ellos es responsable de sus actos respecto del paciente o si sólo uno de ellos debe ser responsable por todos. En esta segunda hipótesis la responsabilidad se concentraría en el médico jefe. En los tribunales chilenos no existe claridad sobre la solución, siendo escasos los casos en que se ha discutido la responsabilidad al interior del equipo médico. Uno de esos casos es la célebre sentencia "Beraud", en la cual se responsabilizó a todos los miembros del equipo por la mal praxis del médico jefe. Se estimó que los otros miembros del equipo debieron estar en conocimiento de cuál cadera debía intervenirse y, además, haberlo representado durante la operación. No comparto esta visión de la responsabilidad al interior del equipo médico. Los subalternos al médico jefe no debieran quedar obligados a representar los actos negligentes, al no estar en una posición de garante ${ }^{6}$.

En la medida que se trata de la responsabilidad médica propiamente tal, es decir de una responsabilidad que no puede ser fundada sino en la culpa, habría que admitir, en primer lugar, que el autor del hecho u omisión culposa es responsable personalmente respecto de la víctima $\mathrm{y}$, enseguida, el médico que no ha cometido ningún acto culposo no puede ser responsable de la culpa de otro médico. Resulta difícil aceptar que un médico pueda ser considerado el subordinado de otro facultativo. Sin embargo, es posible considerar responsable al médico principal por los actos de los otros facultativos aunque él no sea el responsable directo. En esta hipótesis se considera el acto culposo del médico causante directo del daño una prolongación de la actividad del médico principal. Esta explicación puede ser criticada en el ámbito del ejercicio médico. Puede ocurrir que uno de los miembros del equipo aparezca como el responsable, lo que no quiere decir que los otros se encuentren subordinados o bajo sus 
órdenes, pero el médico principal tiene una obligación general de vigilancia del buen funcionamiento del equipo. En este caso su propia culpa podrá serle imputada si el equipo no funciona satisfactoriamente.

\section{Conclusiones}

La evolución de la responsabilidad médica ha sido importante en el último tiempo. Es posible avizorar las siguientes transformaciones de la responsabilidad médica en Chile.

- Una tendencia a excluir la responsabilidad penal de los médicos, salvo situaciones de carácter grave o de actos dolosos. La Fiscalía Nacional ha instruido a los fiscales que en las negligencias médicas intenten juicios abreviados o acuerdos reparatorios. Con este planteamiento se logrará descriminalizar las conductas médicas, situando el problema en el terreno de la responsabilidad civil.

- Una mayor presencia de juicios ante los juzgados civiles con alta presencia de la responsabili-

\section{REFERENCIAS}

1. http://www.sml.cl/pdf/Anuario\%202003.pdf, Cuadro $\mathrm{n}^{\circ} 13$, p. 58. Esta cifra no comprende todo el universo de casos de negligencias médicas, sino sólo aquellos en que se requirió informe pericial al Servicio Médico Legal.

2. Pizarro C. La responsabilidad civil de los hospitales públicos. La ley del auge en perspectiva civil. Estudios de Derecho Civil, Santiago: LexisNexis, 2007 (en prensa). Y la bibliografía citada en la nota (3).

3. Pizarro C. Mirada de un civilista a la reparación dad contractual. El impacto del nuevo proceso penal significará un mayor litigio de la responsabilidad médica ante los juzgados civiles.

- Un aumento de la contratación de seguros de responsabilidad profesional por los médicos y, en particular, por médicos de especialidades más riesgosas: por ejemplo, los anestesistas. El seguro de responsabilidad civil aparece como la forma más idónea para evitar el pago directo de indemnizaciones distribuyendo el costo entre todos los asegurados.

- Una creciente disparidad en las indemnizaciones por concepto de daño moral. Se continuará con la discrecionalidad de los jueces para avaluar el daño moral, lo cual redunda en falta de uniformidad para casos análogos. Si bien es criticable, no se perciben cambios en esta materia.

- De manera propositiva, debiera en un futuro no lejano, tenderse a establecer un régimen común para la responsabilidad civil sin distinción entre los hospitales y clínicas, ni tampoco entre médicos funcionarios o privados. De esta manera se dotará al sistema de mayor coherencia y certeza jurídica ${ }^{7}$.

en el nuevo proceso penal. Gaceta Jurídica 2003; 296: 59-75.

4. LARroumet C. Rapport français. En: La responsabilité Aspects nouveaux. Paris: LGDJ, 2003; 279-93.

5. Barros E. Tratado de responsabilidad extracontractual. Santiago: Jurídica, 2006; p. 240, 663 y 1022. En esta obra, la más reciente, sólo se cita jurisprudencia francesa.

6. Corte Suprema, 20 de junio de 1996, en LexisNexis $n^{\circ}$ identificador 13931.

7. Pizarro C. La responsabilidad médica por el hecho de otro. Revista Chilena de Derecho Privado 2003; 1: 181-205. 